\title{
Enhancement of germination and early seedling growth of rice (Oryza sativa) var. FARO44 by seed priming under normal and drought stressed conditions
}

\begin{abstract}
Rice is an important cereal consumed globally, however, poor germination and non-uniform seedling establishment are major causes of low rice yield in water-limiting arid ecosystems. Seed priming study with $\mathrm{KNO} 3, \mathrm{SA}$ and $\mathrm{SiO} 2$ to enhance germination and seedling growth was carried out with the objectives of (1) to determine the effects of seed priming on germination and early seedling growth, and (2) to evaluate effects of seed priming on physiological growth characteristics of rice seedling under drought stress simulated by polyethylene glycol (PEG6000). Under wellwatered conditions, rice seeds were primed with concentrations of $\mathrm{KNO} 3(2.5 \%, 5 \%, 10 \%, 15 \%$ and $20 \%)$, SiO2 $(2.5 \%, 3 \%, 3.5 \%, 4 \%$ and $4.5 \%)$ and $\mathrm{SA}(0.5,1,1.5,2$, and $2.5 \mathrm{mM})$. While under drought stress, rice seeds were primed with $2.5 \%$ and $5 \% \mathrm{KNO} ; 3 \%$ and $3.5 \% \mathrm{SiO} 2$ and $1 \mathrm{mM}$ and $2.5 \mathrm{mM} \mathrm{SA}$. The results showed that all primed rice seedlings under both well-watered and drought stress conditions had significantly enhanced rice seedling growth parameters of seedling length, plumule length, root length, seedling vigor, seedling biomass and germination index and shorter germination time compared to unprimed controls. However, seed priming with concentrations of $2.5 \%$ and $5 \% \mathrm{KNO} 3 ; 3 \%$ and $3.5 \% \mathrm{SiO} 2$, and $1 \mathrm{mM}$ and $2.5 \mathrm{mM} \mathrm{SA}$ increased rice seedling growth parameters studied better than other concentrations. However, germination percentage was not significantly affected. Thus, priming of FARO44 rice with these concentrations of chemicals is recommended for fast germination, seedling growth and emergence in arid ecosystems.
\end{abstract}

Keyword: Drought stress; Germination percentage; KNO3; SA; Seed priming 